\title{
О ВОЗРАСТЕ ОЗЕРНО-АЛЛЮВИАЛЬНЫХ ОТЛОЖЕНИИ В РАЗРЕЗАХ ДРИЧАЛУКИ И БРИГИТПОЛЕ (СЕВ. БЕЛОРУССИЯ)
}

В настоящее время изотопно-геохимические методы определения возраста, в частности радиоуглеродный метод, являются неотъемлемой частью любых геохронологических и стратиграфических исследований. В связи с повышенным интересом к этому методу аналитики постоянно занимаются усовершенствованием методик регистрации радиоактивных изотопов, расширяют возрастные пределы метода и номенклатуру да тируемых материалов. В последние годы широкое применение нашел рассеянный органический материал (биодетрит), который особенно часто используется при датировании кратковременных колебаний ледников, когда природные условия не были благоприятными для образо вания мощных залежей озерно-болотных отложений. При датировании биодетрита особое значение имеет вопрос о соответствии исследуемого материала предполагаемому периоду накопления изучаемого стратиграфического комплекса. Если обычно при датировании древних образцов торфа или древесины основным отклонением ${ }^{14} \mathrm{C}$-возраста от истинного является омоложение, то при использовании детритового материала равновероятны, по-видимому, как омоложение, так и удревнение. Наглядно это доказано ранее (Stuckenrath и др., 1979) на основе 28 определений возраста органического детрита по ${ }^{14} \mathrm{C}$ с классификацией проб по следующим признакам: способам подготовки материала, гранулометрическим фракциям органического вещества 'и по степени растворимости органики в растворе $\mathrm{NaOH}$. Математико-статистическая обработка полученных данных показала, что статистически значимых различий в пределах каждой классификационной группировки не наблюдается и надежных статистических закономерностей не установлено. Возраст разных фракций органики равен 720-1245 лет. Еще более значительные расхождения ${ }^{14} \mathrm{C}$-возрастов с истинными получены И. Улссон (Olsson, 1979). По ее данным, рассеянное органическое вещество в озерных осадках с истинным возрастом 2800 лет имеет ${ }^{14} \mathrm{C}$-возраст приблизительно 4200 лет, несмотря на обработку $\mathrm{NaOH}$. Такие расхождения вполне понятны, так как никакая обработка не может исключить влияния аллохтонного детрита.

Наше внимание привлекли разрезы в Северо-Восточной Белоруссии, с которыми нас ознакомил и оказал помощь при исследовании Л. Н. Вознячук, посвятивший много лет изучению группы разрезов в верховьях Западной Двины и ее притоков. Накопленный большой фактический материал делает эти разрезы хорошим полигоном для изучения надежности радиоуглеродной хронологии по растительному детриту. При 'изучении их нами был применен также термолюминесцентный метод. Қак известно, возрастные оценки, полученные термолюминесцент. ным методом, отражают время накопления исследуемого стратиграфического комплекса в предпосылке, что в процессе осадконакопления 


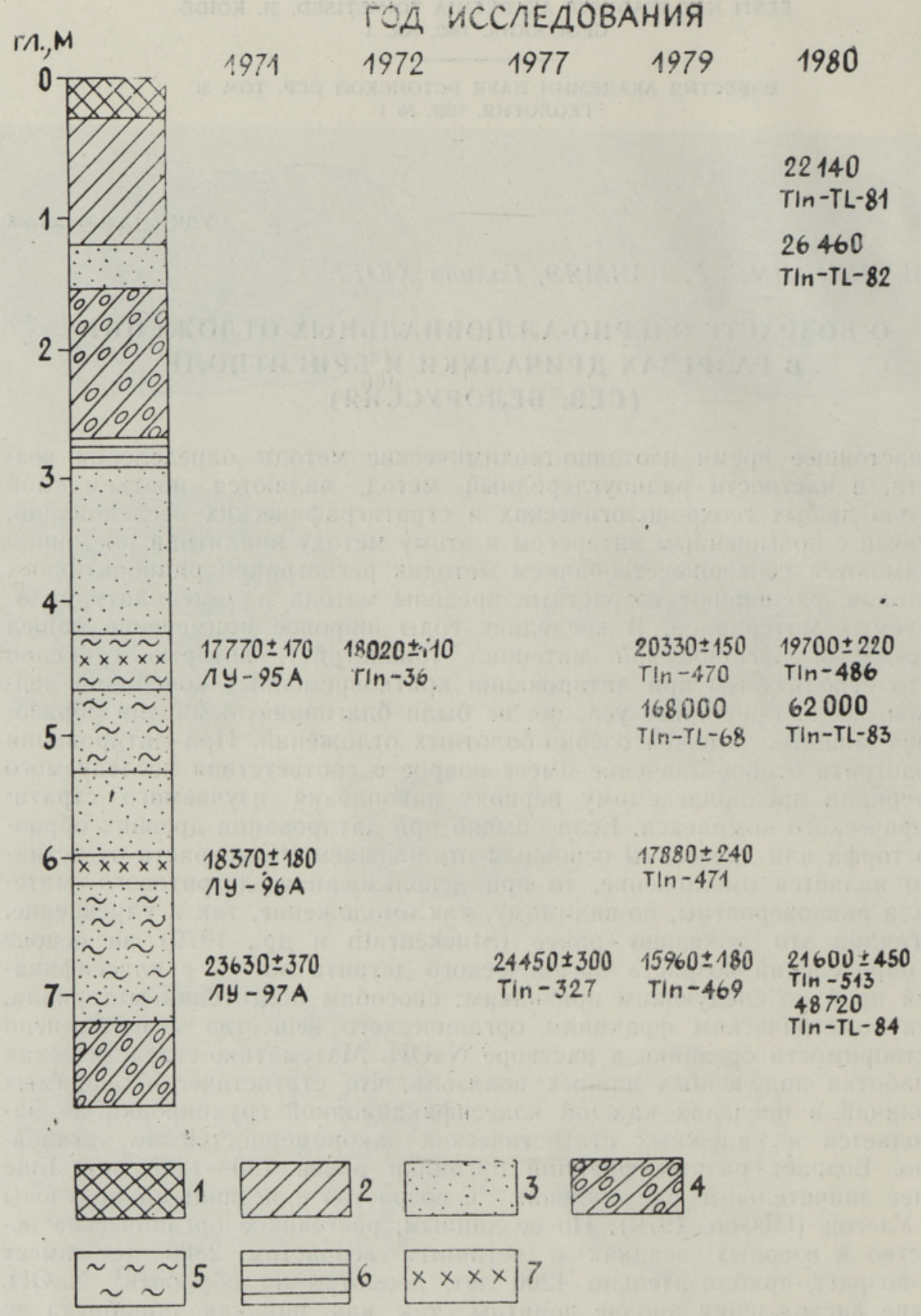

Рис. 1. Разрез Дричалуки и ${ }^{14} \mathrm{C}-$ (TIn) и ТЛ- (TIn-TL) возрасты по образцам, отобранным в разные годы: 1971, по Арсланову и др., 1971; 1972-1980, по данным авторов. 1 - почва; 2 - суглинок; 3 - песок; 4 - валунный суглинок (морена); 5 - супесь; 6 - ленточные глины; 7 - органический детрит.

произошло полное стирание прогенетической светосуммы в используе. мом палеодозиметре - кристалле минерала.

Наиболее известным из исследованных нами разрезов является разрез Дричалуки, который неоднократно описан в литературе (Арсланов и др., 1971; Вознячук, 1972). Разрез находится в 2,5 км к северу от г. Суража на левом берегу р. Усвяча (правый приток Западной Дви- 
ны). В этом разрезе толща озерно-аллювиальных отложений - усвячская свита - покрыта суглинистой мореной и надморенными водноледниковыми отложениями. В верхней части усвячской свиты прослеживаются сингенетические криогенные нарушения. В озерно-аллю. виальных отложениях четко выделяются прослойки растительного дет рита. Видимая часть разреза кончается внизу бурой мореной.

Геохронологически разрез Дричалуки в течение ряда лет тщательно исследовался (рис. 1). Первые ${ }^{14} \mathrm{C}$-определения возраста растительного детрита в прослойках, залегающих на глубинах 120, 170 и 280 см от кровли ленточных глин, были проведены в ЛГУ Х. А. Арслановым (Арсланов и др., 1971). На аснове геологических, палеоботанических и радиоуглеродных нсследований были сделаны два существенных вывода. Во-первых, определено время кульминации последнего оледенения - приблизительно 17000 лет назад (Арсланов и др., 1971). Однако нами неоднократно высказывались сомнения в правильности такого заключения, поскольку разрез Дричалуки находится в 60 км севернее краевых образований, и трудно объяснить столь быстрые темпы отступания края ледника (Пуннинг и др., 1977). Во-вторых, на основе анализа состава макроостатков Ф. Ю. Величкевич (Арсланов и др., 1971) разделил ископаемую флору на шесть групп (гипоарктические виды, гелиофиты, водно-болотные растения, флора таежных и смешанных лесов, термофильные и экзотические виды, неогеновые и девонские виды), причем три последние определил как переотложенные. На основе такой систематизации было сделано важное заключение о крайне суровых климатических условиях в перигляциальной зоне во время осадконакопления. Чтобы установить роль переотложения, нами было проведено датирование отдельных видов ископаемой флоры. М. Илометс (Институт геологии АН ЭССР) выделил из большого количества (около 2 кг) образцов макроостатки ели и березы. Благодаря совершенствованию техники определения ${ }^{14} \mathrm{C}$ в небольших количествах углерода удалось определить возраст обоих видов. Полученные данные - возраст по макроостаткам ели $18100 \pm 500$ (Tln-435) и березы $18700 \pm 1000$ ( $\mathrm{T} \ln -437)$ лет - не позволяют товорить о временном различии между накоплением гипоарктических видов и флорой таежных и смешанных лесов.

Так как у нас возникли сомнения относительно автохтонности растительного детрита, в 1979 и 1980 гг. было проведено повторное детальное исследование обнажения. Из расчистки, заложенной примерно в $30 \mu$ вверх по течению р. Усвяча от расчистки 1972 г. (оттуда отобран образец $\mathrm{T} \ln -36)$, были отобраны образцы на ${ }^{14} \mathrm{C}$ - и ТЛ-определения. Неожиданные данные получены при исследовании образцов, отобранных в 1979 г.: выявилась инверсия возрастов как по ${ }^{14} \mathrm{C}$-, так и по ТЛ-определениям. Получена самая молодая до сих пор дата по усвячской свите - $15960 \pm 180$ лет, которая «омоложает» возраст комплекса на 1800 лет по сравнению с полученным ранее возрастом. Образцы, отобранные из тех же слоев в 1980 г., по ${ }^{14} \mathrm{C}$ имели нормальную возрастную последовательность. По ТЛ анализу время накопления подморенных мелкозернистых песков и алевритов существенно превышало ожидаемое. Полученные первые ТЛ-возрасты по мелкозернистым надморенным пескам отличались существенно более молодыми датами.

В итоге десятилетних геохронологических исследований для самой высокой прослойки детрита получен ${ }^{14}$ С-возраст $17,8-20,3$ тыс. лет, а для самой низкой - $16,0-24,5$ тыс. лет. Для более обоснованных выводов о генезисе и возрасте накопления озерно-аллювиальных и ледниковых толщ в 1979 и 1980 гг. были проведены исследования близ. находящегося разреза на. левом берегу Западной Двины в 3 км вверх по течению от г. Суража у населенного пункта Бригитполе, имеющего 


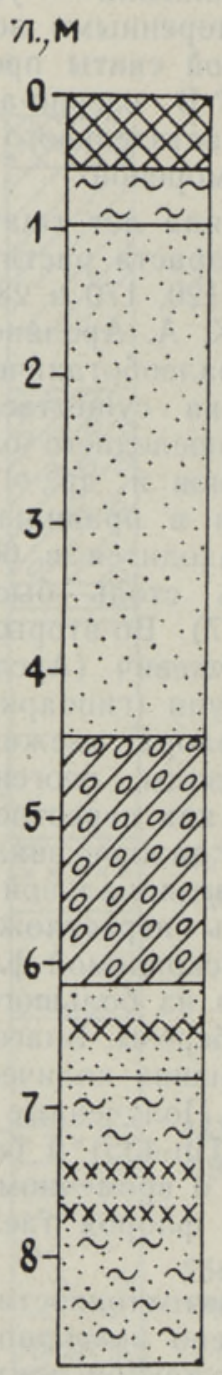

\section{ГОД ИССЛЕДОВАНИЯ}

\section{0 \\ $T / n-T L-85$}

\author{
$29300 \pm 250$ \\ $T \ln -426$
}

$18060 \pm 90$

$\mathrm{TIn}-438$

$17300 \pm 80$

$T \ln -429$

14150

$\Gamma / n-T L-86$
22740

$T / n-T L-87$

Рис. 2. Разрез Бригитполе и ${ }^{14} \mathrm{C}$ - и ТЛ-возрасты (условные обозначения см. на рис. 1).

сходное геологическое строение с разрезом Дричалуки (рис. 2). В разрезе Бригитполе на озерно-аллювиальных отложениях с криогеннымі нарушениями залегают суглинистая морена и комплекс разнозернистых песков. В озерно-аллювиальных отложениях находятся прослойки растительного детрита, прослеживаемые по всей расчистке (длина около $20 \mu)$.

В 1979 г. на ${ }^{14} \mathrm{C}$-анализ были отобраны образцы из самой верхней прослойки примерно $40 \mathrm{~cm}$ ниже подошвы морены и из двух прослоек, залегающих на 120 и 130 cм ниже первой. ${ }^{14} \mathrm{C}$-возрасты были соответственно $29300 \pm 300,18060 \pm 90$ и $17300 \pm 80$ лет. ТЛ-возраст надморенных песков был 27000 лет, а алевритов, залегающих ниже верхнего прослоя растительного детрита, даже 14150 лет. Примерно такие же возрасты были получены и по сборам 1980 г. Мелкозернистый песок, залегающий выше морены, имеет возраст, согласующийся с соответствующими возрастами по разрезу Дричалуки.

18 радиоуглеродных и 8 термолюминесцентных датировок, а также 
палеонтологические данные Ф. Ю. Величкевича позволяют сделать определенные выводы о процессе накопления озерно-аллювиальных и ледниковых отложений в разрезах Дричалуки и Бригитполе. Из пяти серий ${ }^{14} \mathrm{C}$-датировок в трех нарушена нормальная последовательность возрастов, что говорит о аллохтонности материала. Верхи исследуемого стратиграфического комплекса датированы 'интервалом 17,8-29,3 тыс. лет, а подошва - интервалом 16,0-23,6 тыс. лет. Термолюминесцентные датировки извлеченного из усвячской свиты кварца и полевого шпата варьируют в интервале 29,6-168 тыс. лет.

Полученные геохронологические данные подтверждают предположение Ф. Ю. Величкевича (1973), который не исключал возможности случайного скопления макроостатков. По-видимому, органическая седиментация в старицах долины р. Западной Двины произошла во время деградации ледника, когда в Суражской котловине были широко распространены поля мертвых льдов. Водной эрозией были вымыты органические остатки из средневалдайских и микулинских отложений. В peзультате случайного перемешивания инситного и аллохтонного органического детрита возможны любые возрасты валового образца, причем самая молодая датировка наилучшим образом отражает время накопления исследуемых отложений, являясь при этом максимальной. Это значит, что аллювиальные отложения стали формироваться не ранее чем 16 тыс. лет назад. По всей вероятности, часть детритового материала происходит из близнаходящихся разрезов с микулинскими отложениями. В пользу такого заключения говорят и ТЛ-даты, которые по величинам превосходят радиоуглеродные, что вызвано неполнотой сти. рания древней светосуммы в процессе переотложения.

Естественно, что эти датировки, особенно $15960 \pm 180$ лет, не могут быть связаны с возрастом кульминации последнего оледенения. На наш взгляд, датированный в старицах р. Западной Двины материал вполне мог накопиться после деградации ледника. Относительно маломощный двинско-касплянский ледниковый язык в ходе деградации ледника из-за широкого развития древних эрозионных ложбин быстро переходил от активного состояния к пасоивному и местами даже в мертвые льды. Погребенные мертвые льды могли существовать несколько тысяч лет. В аналогичных условиях погребенные льды наблюдались нами на архипелаге Шпицберген, где они были покрыты морскими отложениями возрастом около 8000 лет.

В результате постепенного потепления и интенсивной водной эрозии лед растаял, и аллювиальные отложения покрылись солифлюкционными. Полученные нами ${ }^{14} \mathrm{C}$-датировки разрезов Дричалуки ІІ Бригитполе, таким образом, скорее всего отражают время отложения и погребения растительного детрита. Край ледника в это время находился уже значительно севернее г. Суража.

Термолюминесцентные датировки покрывающих морену песков связаны с возрастом ледниковых отложений и отражают возраст накопления морены. В ходе последующего вымывания и сортировки моренного материала стирания светосуммы не пронзошло. Так как у нас нет сведений о полноте стирания светосуммы в процессе формирования морены, полученные данные, по-видимому, превышают цистинные. Несмотря на это, оценка возраста ледниковых отложений (22 тыс. лет) весьма хорошо согласуется с представлениями о кульминации северо европейского и североамериканского ледниковых покровов в интервале 20-22 тыс. лет назад.

Проведенные исследования показывают как осторожно надо относиться к датировкам по детритовому материалу. Получение даже серии датировок (Арсланов и др., 1971) не является достаточным доказательством в пользу автохтонности изучаемых отложений, 
Арсланов Х. А., Вознячук Л. Н., Величкевич Ф. Ю., Махнач Н. А.. К алечиц Е. Г., П е т ров Г. С. Возраст максимальной стадин последнего оледенения на междуречье Западной Двины и Днепра. - Докл. АН СССР. $1971,196,161-164$.

Величкевич $Ф$. Ю. Антропогеновые семенные флоры Белоруссии и смежных областей. Мннск, 1973.

В ознячук Л. Н. Возраст максимальной стадии валдайского оледенения на северозападе СССР и основные фазы деградации ледника. - В кн.: Вопросы четвертичной геологии. Рига, 1972, 29-43.

Пу н н и н Я Я.-M. К., Р аук а с А. В., Р а я м э Р. А. Изотопно-геохимические и физические методы в палеогляциологических исследованиях. - В кн.: Мат. гляциол. исслед. Хроника, обсуждения. М., 1977, вып. 29, 189-195.

Olsson, I. U. A warning against radiocarbon dating of samp'es containing litt.e carbon. - Boreas, 1979, 8, 203-207.

Stuckenrath, R., Miller, G. H., And rews, J. T. Problems of radiocarbon dating Holocene organic-bearing sediments, Cumberland Peninsula, Baffin Island N.W.T. Canada. - Arctic and Alp. Res., 1979, 11, 109-120.

Ннститут геологии

Академии наук Эстонской ССР
Поступила в редакцию

$15 / \mathrm{V} 1981$

\section{J.-M. PUNNING, R. RAJAMAE, Galina HOTT}

\section{JÄRVELIS-ALLUVIAALSETE SETETE VANUSEST DRITŚALUKI JA BRIGITPOLE LÄBILOIKEIS (POHJA-VALGEVENE)}

Artikkel sisa!dab Dritšaluki ja Brigitpole läbilōigete geokronoloogilise uurimise tulemusi. Need-läbilōiked olid a:useks hilisvaldai jäätumise maksimaalse leviku dateerimisel ning selle ajalōigu pa'eogeograafilisel iseloomustamisel. 18 proovi ${ }^{14} \mathrm{C}$-dateeringust järeldub, et dateeritav materjal - biodetriit - on sekundaarset päritolu ning tõenäo:ise:t koosneb nii kohapeal moodustunud kui ka mikuulino jäävaheaja setetest väljapestud materja:i mehaanilisest segust. Saadud vanustele (16000-30000 aastat) tuginedes võib ee:dada, et orgaani'ist ainet sisaldav aleuriit on moodustunud ajal, mil aktiivne liustikukeel asus uuritud leiukohtadest tunduvalt põhja pool ning Suraži nõos levisid passiivse jää väljad. Aleuriiti kattev moreen võib seega olla solifluktsioonilist päritolu.

\section{J.-M. PUNNING, R. RAJAMAE, Galina HOTT}

\section{ON THE AGE OF LIMNIC-ALLUVIAL SEDIMENTS IN DRICHALUKY AND BRIGITPOLE SECTIONS (NORTH BYELORUSSIA)}

The paper represents the results obtained through geochrono'ogical study of the Drichaluky and Brigitpole sections. Those sections served as a basis for the dating of the maximal distribution of the Late-Valdaian glaciation and for the compilation of pa:aeogeographical characteristics of the above time interval. ${ }^{14} \mathrm{C}$ datings, 18 in all, refer to the secondary origin of the dated material - biodetritus. Most like:y it represents a mechanical mixture of the material outwashed from the sediments either of local origin or dating from the Mikulian Interglacial. The data obtained (16-30 thousand years) indicate that the silt containing organic matter was formed at the time when the active g'acier tongue was situated considerably farther northwards than the sections studied, and the passive ice-fields were of wide distribution in the Surazhi depression. Consequently, the till overlying silt may be of solifluctional origin. 